\title{
Spectrophotometric Determination of Malondialdehyde in Urine Suitable for Epidemiological Studies
}

\author{
Tin Weitner, Suzana Inić, Jasna Jablan, Mario Gabričević, Ana-Marija Domijan*
}

\author{
1 Faculty of Pharmacy and Biochemistry, University of Zagreb, Ante Kovačića 1, 10000 Zagreb, Croatia \\ * Corresponding author's e-mail address: adomijan@pharma.hr
}

RECEIVED: May 4, 2016 * REVISED: June 14, 2016 * ACCEPTED: June 14, 2016

Abstract: A reliable method for spectrophotometric determination of urinary malondialdehyde (MDA), according to the thiobarbituric acid (TBA) assay, is described. To account for matrix interference and differences in individual urine composition, standard addition procedure was applied. The method is adequately selective ( $\mathrm{LOQ}=0.09 \mu \mathrm{M}$ in the presence of $0.1 \mathrm{M}$ creatinine and $0.5 \mathrm{M}$ urea) and reliable (within-day and between-day variability of less than $5 \%$ ). The mean level of urinary MDA was $1.52 \pm 0.73 \mu \mathrm{M}$ that is in good agreement with spectrofluorometric determination $(1.20 \pm 0.56 \mu \mathrm{M} ; p=0.085)$ as well as with previous studies that used HPLC. Furthermore, it is demonstrated that MDA is stabile in urine at room temperature for $24 \mathrm{~h}$ and when stored at $-20^{\circ} \mathrm{C}$ for 6 months. The described method enables simple, rapid and cost-effective determination of urinary MDA as a relevant and non-invasive marker of "whole-body" oxidative stress.

Keywords: malondialdehyde, thiobarbituric acid assay, urine, interferences, stability.

\section{INTRODUCTION}

$\mathbf{T}$ HE dicarbonyl malondialdehyde (MDA) is one of the products of lipid peroxidation. ${ }^{[1,2]}$ Lipid peroxidation is a process in biological systems initiated by an attack of reactive oxygen species (ROS) on polyunsaturated fatty acids, major constituents of plasma membranes. The first products of lipid peroxidation are unstable lipid peroxides that are further converted by consecutive reactions of oxidation, rearrangements and scission into more stable carbonyl compounds, among which is MDA. ${ }^{[2,3]}$

The condition of imbalance between the metabolic production of reactive species and the cellular ability to scavenge the reactive metabolites or repair the incurred damage is oxidative stress. This condition is connected to the development of various diseases, including cancer. ${ }^{[3,6]}$ Therefore, it is important to find reliable markers to follow the extent of oxidative stress. The level of MDA as a final product of lipid peroxidation in specific tissue is considered as a marker of oxidative stress in that particular tissue, and MDA level in plasma and urine represents "whole-body" oxidative stress. ${ }^{[4,7]}$ Drury at al. ${ }^{[4]}$ demonstrated by com- paring plasma and urine samples that urinary MDA level is good marker of "whole-body" oxidative stress in populations without renal disease.

Considering that urine has several practical advantages over plasma (urine is easier to collect, and collection is readily accepted by participants of epidemiological studies), the aim of this study was to set a reliable and rapid method for determination of MDA in urine as a relevant and non-invasive marker of "whole-body" oxidative stress. This study seems particularly relevant due to the emerging importance of urine as ideal source of biomarkers that can reflect early-stage systemic changes. ${ }^{[8]}$ Recently published methods for determination of MDA in urine are employing HPLC, LC-MS/MS, GC-MS/MS or chemiluminescence. ${ }^{[9-12]}$ These methods are time-consuming and not particularly suitable for automatization that is especially important in studies with large number of samples. Moreover, the required equipment is not readily available in laboratories worldwide, particularly in developing countries. Therefore, spectrophotometric and spectrofluorometric methods for the determination of MDA are revisited in this study as a simple, cost-effective and efficient alternative. The 
application of the methods described in this study on microplate readers could easily provide a much higher throughput than the more demanding instrumental methods.

\section{EXPERIMENTAL}

\section{Chemicals and Standard Preparation}

Chemicals 2-thiobarbituric acid (TBA), o-phosphoric acid $\left(\mathrm{o}-\mathrm{H}_{3} \mathrm{PO}_{4}\right)$, urea and creatinine were from Kemika, Zagreb, Croatia. 1,1,3,3-tetraethoxypropane (malondialdehyde bisdimethylacetal) (Sigma, St. Louis, MO, USA) was used as MDA standard. All chemicals were of p.a. grade and used without further purification.

MDA stock solution (in concentration of $3.0 \mathrm{M}$ ) was prepared by diluting MDA standard in MilliQ water. MDA stock solution was stored in aliquots at $-20{ }^{\circ} \mathrm{C}$. Working standards in MilliQ water (ranging from 0.1 to $10.11 \mu \mathrm{M}$ ) were prepared fresh daily.

\section{Equipment}

Spectrophotometric measurements were performed on Agilent 8453 UV-Vis spectrophotometer equipped with UVVisible ChemStation software (Agilent Technologies, CA, USA) for data collection and analysis. Spectra were recorded at room temperature in quartz cuvettes with $1 \mathrm{~cm}$ path length.

Fluorescence spectra were measured at $25{ }^{\circ} \mathrm{C}$ by OLIS RSM 1000F spectrofluorometer (Olis Inc., Bogart, Georgia, USA), equipped with a thermostatted cell holder and OLIS Globalworks software for data collection and analysis. Fluorescence units (f. u.) are given as a ratio of signals obtained from sample and reference photomultiplier tubes. Spectra were recorded at room temperature in quartz cuvettes with $1 \mathrm{~cm}$ excitation path length and $0.2 \mathrm{~cm}$ emission path length. Each reported spectrum (or singlewavelength fluorescence) is an average of 10000 rapidscan fluorescence measurements collected in 10 seconds.

\section{Sample Collection and Preparation}

Urine spot samples from healthy volunteers of both genders were collected in sterile containers. Testing of the method was performed on $n=10$ urine samples. For testing the stability of MDA in urine at room temperature, additional urine samples $(n=5)$ were collected and the level of MDA in the same sample was monitored for 24 hours. For testing the stability of MDA in urine at $-20^{\circ} \mathrm{C}$, urine samples $(n=7)$ were collected and stored in aliquots, followed by monitoring the level of MDA in intervals throughout 6 months. The study was approved by the Ethics Committee for Experimentation of Faculty of Pharmacy and Biochemistry, University of Zagreb, and observed the ethical principles of the Declaration of Helsinki.

Sample preparation procedure for determination of MDA in urine was as follows: to $400 \mu \mathrm{l}$ of urine $250 \mu \mathrm{l}$ of TBA (0.6\%) and $750 \mu \mathrm{lo}-\mathrm{H}_{3} \mathrm{PO}_{4}(1 \%)$ were added. The reaction mixture was heated at $90{ }^{\circ} \mathrm{C}$ for $30 \mathrm{~min}$ in a temperature-controlled heating block (G-Term 035, Fratelli Galli, Milano, Italy). Reaction (Figure 1) was stopped by placing samples on ice. The MDA concentration was measured spectrophotometrically at $\lambda=532 \mathrm{~nm}\left(A_{532}\right)$ and spectrofluorometrically at $\lambda_{\mathrm{em}}=553 \mathrm{~nm}\left(\lambda_{\mathrm{ex}}=515 \mathrm{~nm} ; F_{553}\right)$.

Since essentially no urine sample is MDA-free, MDA concentration was determined by standard addition procedure. ${ }^{[13]}$ Urine composition varies due to differences in individual water balance, environmental conditions, physical exercise and nutrition ${ }^{[14]}$ and the standard addition method provides reasonable means to account for possible matrix interference effects, i.e. recovery. ${ }^{[15]}$ For each urine sample, a total of 4 samples were prepared for measurement as follows: blank sample (no reagent added), test sample and two additional test samples with added known concentration of MDA at two levels (Table 1). The signal value for the blank sample has been subtracted from the samples with added reagent, thus accounting for baseline interferences. All samples underwent same sample preparation procedure described above. Results were expressed as micromoles per liter $(\mu \mathrm{M})$.<smiles>CCCC(=O)NC(=S)NC(=O)CC(=O)NC(O)=NC(O)=NC(=S)NC(=S)[18CH]C=O</smiles>

MDA

TBA

MDA-TBA ${ }_{2}$ adduct

Figure 1. Reaction of malondialdehyde (MDA) with 2 molecules of 2-thiobarbituric acid (TBA). 
Table 1. Sample preparation for sample addition procedure

\begin{tabular}{|c|c|c|c|c|c|}
\hline Sample & $V$ (urine) / $\mu \mathrm{l}$ & $V\left(\mathrm{o}-\mathrm{H}_{3} \mathrm{PO}_{4}, 1 \%\right) / \mu \mathrm{l}$ & $V($ TBA, $0.6 \%) / \mu \mathrm{l}$ & $V($ MilliQ water) / $\mu l$ & $V(\text { Standard })^{(\mathrm{a})} / \mu \mathrm{l}$ \\
\hline Blank & 400 & 750 & - & 260 & - \\
\hline Reagent & 400 & 750 & 250 & 10 & - \\
\hline Standard level 1 & 400 & 750 & 250 & 5 & 5 \\
\hline Standard level 2 & 400 & 750 & 250 & - & 10 \\
\hline
\end{tabular}

(a) Working standard $0.3035 \mathrm{mM}$ solution was prepared fresh daily by diluting MDA stock solution $(c=3.0 \mathrm{M})$ in MilliQ water.

\section{Statistical Analysis}

Data are expressed as mean \pm standard deviation. Statistical analysis of the data (descriptive statistics and linear regression) was performed with Statistica 8.0 software (Stat Soft Ltd., Bedford, UK). Paired t-test was used to analyze differences between methods and samples. Differences were considered significant for values of two-tail $p<0.05$.

\section{RESULTS AND DISCUSSION}

\section{Sample Preparation and Testing for Possible Interferences}

MDA in reaction with TBA (TBA assay) forms an intensely colored adduct (MDA-TBA 2 ; Figure 1 ) that is easily assessed spectrophotometrically or spectrofluorometrically, and therefore, the method is frequently used to follow extent of lipid peroxidation in biological samples. ${ }^{[3,4]}$ The reaction of MDA and TBA depends on temperature and $\mathrm{pH}$, but too strong acid and high temperature (so-called "harsh conditions") can lead to overestimation of results due to artefactual peroxidation of sample constituents. ${ }^{[16]}$ In this study the reaction mixture was heated at $90{ }^{\circ} \mathrm{C}$ for 30 minutes, since the experimental data indicate that these conditions yield maximal product formation (Figure 2).

Literature references also indicate that the TBA assay lacks selectivity: TBA is reacting not only with MDA, but also with other components of biological samples, such as sugars, amino acids, bilirubin and albumin. ${ }^{[3,17]}$ To avoid false-positive results and overestimation of MDA levels, use of HPLC is suggested, but that prolongs the duration of analysis and increases its cost. Therefore, in this study, possible interferences for spectrophotometric and spectrofluorometric determination of MDA levels in urine were tested. According to the literature, possible interferences for urinary MDA determination are creatinine and urea. ${ }^{[18,19]}$ Creatinine and urea were prepared in concentrations higher than expected in human urine, i.e. values higher than normal ( $100 \mathrm{mM}$ vs. $16 \mathrm{mM}$ and $0.5 \mathrm{M}$ vs. 0.39 $M$ for creatinine and urea, respectively), ${ }^{[14,19]}$ and underwent the same sample preparation procedure as described for urine samples. The spectra shown in Figure 3 indicate

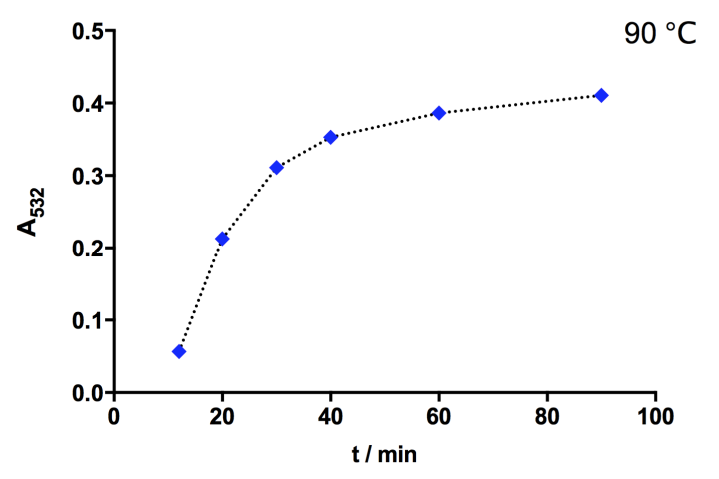

Figure 2. Derivatization rate of malondialdehyde (MDA) standard in MilliQ water $(c=6.07 \mu \mathrm{M})$ and 2-thiobarbituric acid (TBA) at $90^{\circ} \mathrm{C}$.

a)

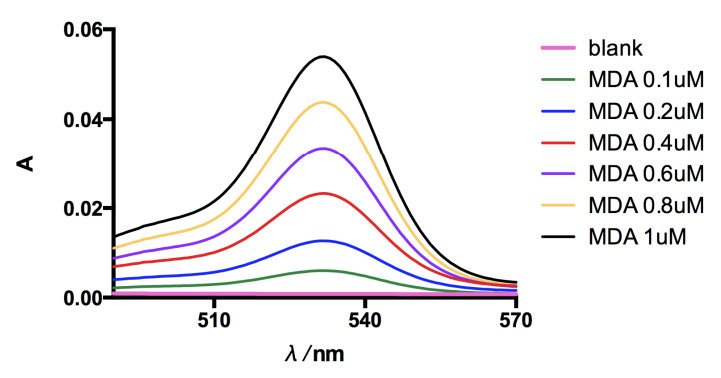

b)

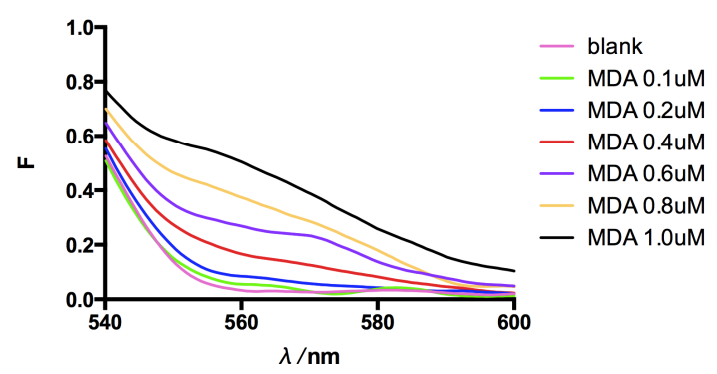

Figure 3. Spectra of MDA standard in MilliQ water in the presence of $0.1 \mathrm{M}$ creatinine and $0.5 \mathrm{M}$ urea obtained: spectrophotometrically (a); spectrofluorometrically (b). 
Table 2. Validation parameters of spectrophotometric and spectrofluorometric determination of MDA in urine gained with MDA standards prepared in MilliQ water. LoD and LoQ values are given in the presence of $0.1 \mathrm{M}$ creatinine and $0.5 \mathrm{M}$ urea

\begin{tabular}{ccc}
\hline Parameter & Spectrophotometric & Spectrofluorometric \\
\hline Within-day variability, CV / \% & 3.76 & 2.72 \\
Between-day variability, CV / \% & 4.39 & 4.27 \\
Limit of detection, LoD / $\mu \mathrm{M}$ & 0.03 & 0.10 \\
Limit of quantification, LoQ / $\mu \mathrm{M}$ & 0.09 & 0.30 \\
\hline
\end{tabular}

that, in fact, urea and creatinine do not significantly interfere with spectrophotometric or spectrofluorometric determination of MDA-TBA 2 adduct.

\section{Validation of the Method}

Linearity of the method was tested using MDA standards prepared both in MilliQ water or urine, in the concentration range from 0.5 to $10.11 \mu \mathrm{M}$ (spectrophotometry) or 0.5 to $6.07 \mu \mathrm{M}$ (spectrofluorometry). All calibration curves were linear for both methods and either sample type (Figure 4). Parameters of method validation with MDA standards prepared in MilliQ water are given in Table 2. The repeatability (within-day variability) was evaluated by determining MDA level at three different concentrations, five repetitions each. Mean coefficient of variation (CV) for within-day repetition was $3.76 \%$ and $2.72 \%$ for spectrophotometric and spectrofluorometric determination, respectively. The reproducibility (between-day variability) was tested by measuring MDA level of same MDA standard daily for 6 consecutive days. Between-day variability CV was $4.39 \%$ and $4.27 \%$ for spectrophotometric and spectrofluorometric determination, respectively. a) MDA in MiliQ water

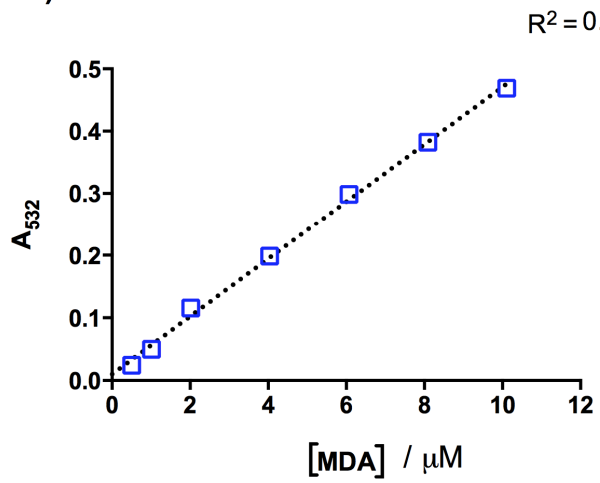

c)

- MDA in MiliQ water

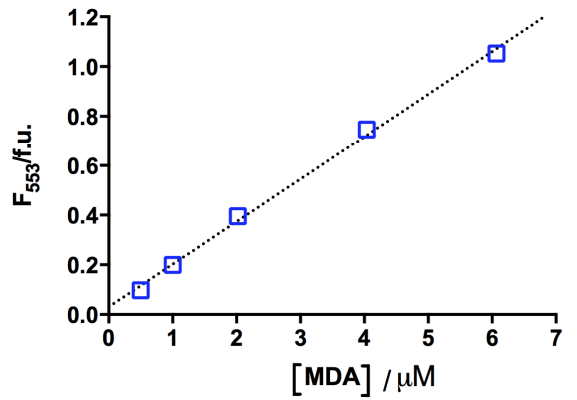

b) - MDA in urine

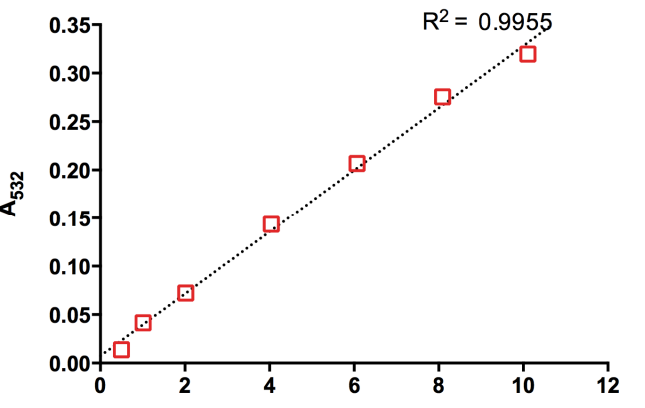

$[\mathrm{MDA}] / \mu \mathrm{M}$

d) MDA in urine $\mathrm{Y}=0.01323^{*} \mathrm{X}+0.006030$ $R^{2}=0.9901$ $R^{2}=0.9975$

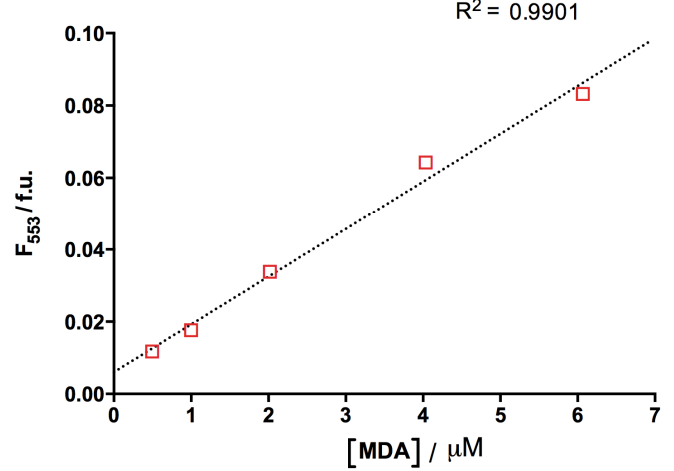

Figure 4. Calibration curves of MDA standard: spectrophotometric determination $(\lambda=532 \mathrm{~nm})$ in MilliQ water (a); spectrophotometric determination $(\lambda=532)$ in urine $(b)$; spectrofluorometric determination $\left(\lambda_{\mathrm{em}}=553 \mathrm{~nm}\left(\lambda_{\mathrm{ex}}=515 \mathrm{~nm}\right)\right)$ in MilliQ water (c); spectrofluorometric determination $\left(\lambda_{\mathrm{em}}=553 \mathrm{~nm}\left(\lambda_{\mathrm{ex}}=515 \mathrm{~nm}\right)\right)$ in urine $(\mathrm{d})$. Linear regression parameters are given on each plot. 
Special care was taken in estimation of limit of detection (LoD) and limit of quantification (LoQ) values. For this purpose, an additional calibration was performed in MilliQ water in the range from 0.1 to $1 \mu \mathrm{M}$, in the presence of $0.1 \mathrm{M}$ creatinine and $0.5 \mathrm{M}$ urea (Figure 5), in order to account for possible interferences. The values were calculated as LoD $=3.3 s_{y} / a$, and LoQ $=10 s_{y} / a$, where $s_{y}$ is the standard deviation of the linear regression intercept, and $a$ is the linear regression slope. The results of LoQ and LoD determination are given in Table 2. Unexpectedly, the spectrophotometric method was found to be more sensitive (approximately 3-fold lower values of LoD and LoQ), which can be attributed to the rapid-scanning fluorescence measurement technique that was chosen for speed (only $10 \mathrm{sec}-$ onds per sample). Additionally, the fluorescence signal apparently deviates from linearity for [MDA] $<0.2 \mu \mathrm{M}$ in the presence of $0.1 \mathrm{M}$ creatinine and $0.5 \mathrm{M}$ urea (Figure $5 b)$, which is also reflected in the higher value of $L o Q=0.3$ $\mu \mathrm{M}$ vs. $\mathrm{LoQ}=0.09 \mu \mathrm{M}$ for absorbance.

\section{Urine Samples}

The levels of MDA in urine samples ( $n=10$; adults, both genders, average age $30.8 \pm 14.13$ years, range $21-58$ ) determined spectrophotometrically were in the range from 0.59 to $2.36 \mu \mathrm{M}$ and mean level was $1.52 \pm 0.73 \mu \mathrm{M}$. The same samples were analyzed spectrofluorometrically and similar results were obtained, with MDA levels in the range from 0.66 to $2.03 \mu \mathrm{M}$ and mean level of $1.20 \pm 0.56 \mu \mathrm{M}$. The values obtained by the two methods were not significantly different $(p=0.085)$. Representative calibration curves for urine samples obtained spectrophotometrically or spectrofluorometrically by the sample addition method are given in Figure 6.

In a previous study by Drury et al. ${ }^{[4]}$ urinary MDA level of preterm infants $(n=50)$ was in the range from 0.5 to $2.5 \mu \mathrm{M}$, determined by HPLC with UV-Vis detector. In an epidemiological study conducted on 44 Chinese volunteers ( 22 children and their mothers; average 23.4 years old, range 10-46), mean MDA level in urine was $1.52 \pm 0.20 \mu \mathrm{M}$, determined by HPLC with fluorescent (FL) detector. ${ }^{[20] ~ I n ~}$ the same study, when testing the stability of MDA in urine (at $-20^{\circ} \mathrm{C}$ for $16 \mathrm{~h}$ ) mean level of MDA in urine of 10 subjects was as high as $2.43 \pm 0.19 \mu \mathrm{M}$. In another epidemiological study that included 500 urine samples collected in Korea (including adults, primary and middle school students, and infants), MDA in urine was assessed by HPLC with FL detector and mean MDA concentration was $2.15 \pm 1.6 \mu \mathrm{M}$ (range from 0.01 to $11.86 \mu \mathrm{M}){ }^{[21]}$ The values for MDA levels in urine reported in this study are in good agreement with the previous studies that employed HPLC separation methods for MDA determination (Table 3). The results for urinary MDA obtained spectrophotometrically were additionally verified spectrofluorometrically. These results indicate that

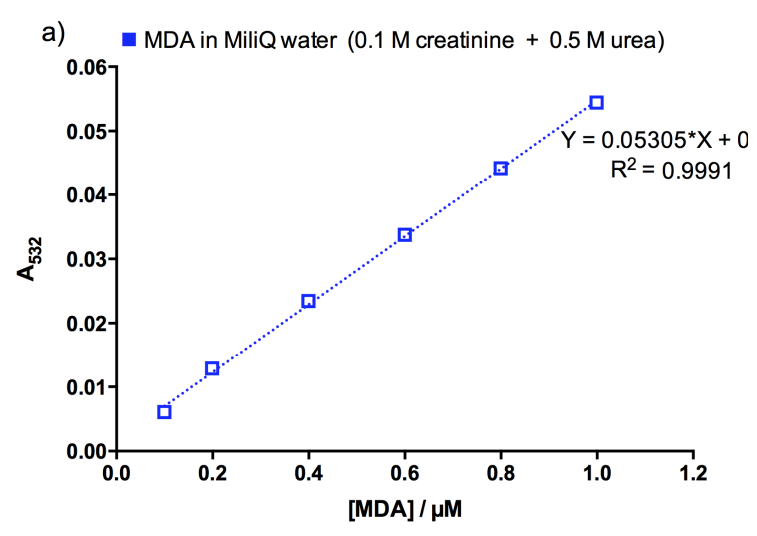

b) MDA in MiliQ water ( $0.1 \mathrm{M}$ creatinine + $0.5 \mathrm{M}$ urea)

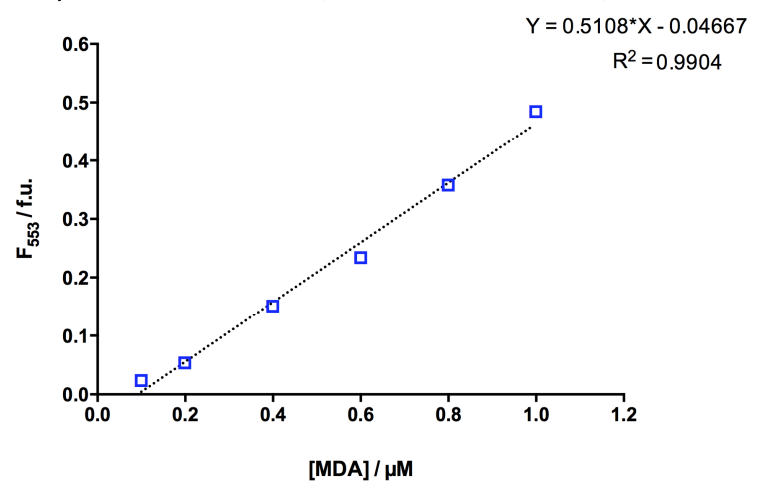

Figure 5. Calibration curves of MDA standard in MilliQ water for determination of LoD and LoQ values in the presence of $0.1 \mathrm{M}$ creatinine and $0.5 \mathrm{M}$ urea: spectrophotometric determination $(\lambda=532 \mathrm{~nm})(\mathrm{a})$; spectrofluorometric determination $\left(\lambda_{\mathrm{em}}=553 \mathrm{~nm}\left(\lambda_{\mathrm{ex}}=515 \mathrm{~nm}\right)\right)$ (b). Linear regression parameters are given on each plot.

the described spectrophotometric method can be used for determination of MDA in urine in order to follow the extent of "whole-body" oxidative stress. The method is particularly suitable for epidemiological studies, in which fast and reliable determination of MDA in a large number of samples is required.

\section{Stability of MDA in Urine Samples}

In epidemiological studies a large number of samples are collected and stored; therefore it was important to verify the stability of MDA in stored urine samples. Kumar et al. ${ }^{[22]}$ observed that MDA is unstable when stored at $-20^{\circ} \mathrm{C}$ for longer than three weeks, with an observed increase of MDA level in plasma stored for 1 month to 1 year. Lee and Kang ${ }^{[20]}$ showed that MDA is stable in urine at room temperature and at $-20^{\circ} \mathrm{C}$ for 16 hours. In this study, the stability of MDA in urine was assessed at room temperature for $24 \mathrm{~h}$ and when stored at $-20^{\circ} \mathrm{C}$ for 6 months. To test MDA stability at room temperature, MDA level in urine samples $(n=5)$ was assessed immediately after collection, 
Table 3. Comparison of the MDA levels in human urine reported previously obtained by HPLC methods and the described spectrophotometric (UV/Vis) and spectrofluorometric $(\mathrm{FL})$ method reported in this study

\begin{tabular}{ccccc}
\hline Author & $\begin{array}{c}\text { Number of } \\
\text { urine samples }\end{array}$ & Range $/ \mu \mathrm{M}$ & Mean value / $\mu \mathrm{M}$ & Method \\
\hline This study & $n=10$ & $0.59-2.36$ & $1.52 \pm 0.73$ & UV/Vis \\
This study & $n=10$ & $0.66-2.03$ & $1.20 \pm 0.56$ & $\mathrm{FL}$ \\
Drury et al..$^{[4]}$ & $n=50$ & $0.5-2.5$ & - & HPLC-UV/Vis \\
Lee and Kang ${ }^{[20]}$ & $n=10$ & - & $2.43 \pm 0.19$ & $\mathrm{HPLC}-\mathrm{FL}$ \\
Lee and Kang & $n=44$ & - & $1.52 \pm 0.20$ & $\mathrm{HPLC}-\mathrm{FL}$ \\
Kil et al. ${ }^{[21]}$ & $n=500$ & $0.01-11.86$ & $2.15 \pm 1.60$ & $\mathrm{HPLC}-\mathrm{FL}$ \\
\hline
\end{tabular}

a)

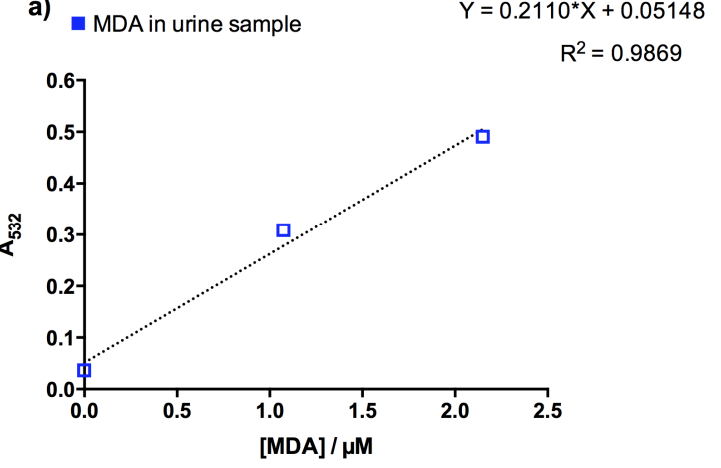

b)

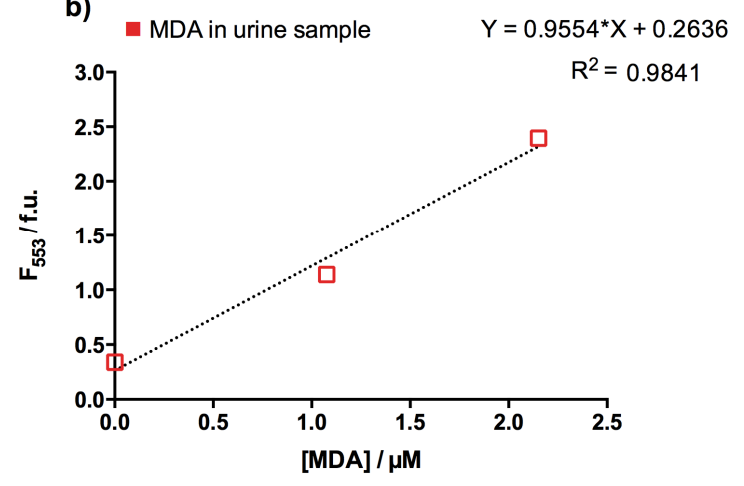

Figure 6. Representative calibration curves for urine samples obtained by the sample addition method. The concentrations of added standard are given on the $\mathrm{x}$-axis: spectrophotometric method (a); spectrofluorometric method (b). Linear regression parameters are given on each plot. The concentration of MDA in the urine sample was then calculated as $[\mathrm{MDA}]=-b / a$, where $b$ and $a$ are the intercept and the slope of the regression line $(0.86 \mu \mathrm{M}$ and $0.97 \mu \mathrm{M}$ for spectrophotometric and spectrofluorometric measurements, respectively).

and 1,2 and $24 \mathrm{~h}$ afterwards. The absorbance signal $\left(A_{532}\right)$ of TBA-treated urine samples kept at room temperature for $24 \mathrm{~h}$ was not significantly changed ( $p=0.39$ ) (Figure 7a). Similarly, no significant change in $A_{532}$ of TBA-treated urine
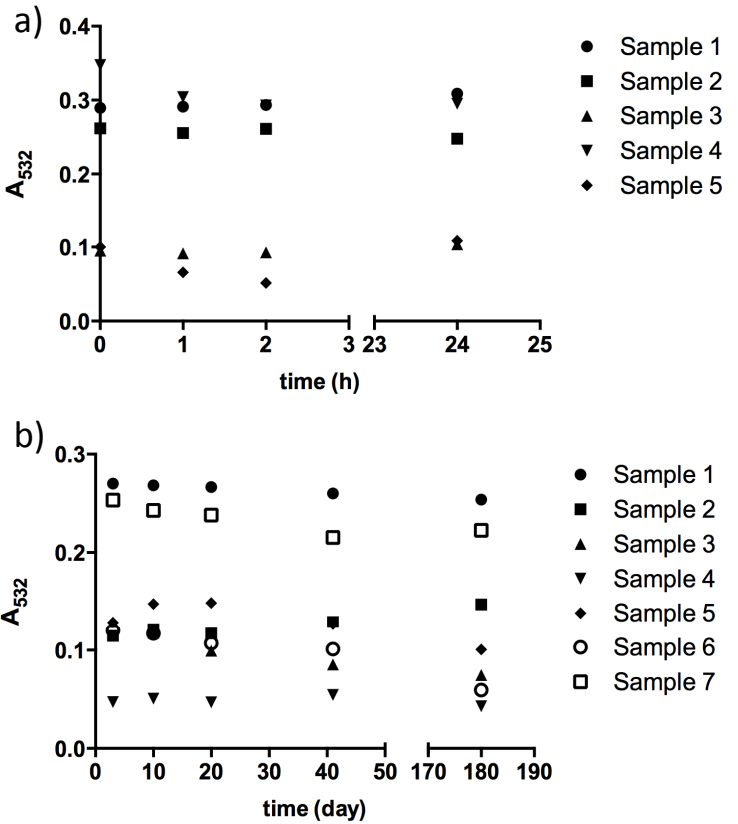

Figure 7. Stability of MDA in urine samples: 24-hour study of samples stored at room temperature (a); 6-month study of samples stored at $-20^{\circ} \mathrm{C}(\mathrm{b})$.

samples $(n=7)$ stored at $-20^{\circ} \mathrm{C}$ for up to 6 months ( $3-180$ days) was observed ( $p=0.81$ ) (Figure 7b).

\section{CONCLUSION}

This study describes a spectrophotometric method for simple, rapid and cost-effective determination of MDA in urine that is particularly suitable to studies that include a large number of samples. Testing for interferences demonstrated that the spectrophotometric method is adequately selective ( $\mathrm{LoQ}=0.09 \mu \mathrm{M}$ in the presence of $0.1 \mathrm{M}$ creatinine and $0.5 \mathrm{M}$ urea) and reliable (within-day and between-day variability of less than $5 \%$ ). The obtained results were additionally confirmed spectrofluorometrically, and the values of MDA levels are in good agreement with previous 
studies performed with HPLC separation of MDA-TBA adduct. Furthermore, it is demonstrated that MDA is stabile in urine at room temperature for $24 \mathrm{~h}$ and when stored at $-20^{\circ} \mathrm{C}$ for 6 months.

Acknowledgment. The authors greatly acknowledge financial support of University of Zagreb (grants No. BM027/15 and No. BM034/15).

\section{REFERENCES}

[1] H. Esterbauer, K. H. Cheeseman, Method in Enzymol. 1990, 186, 407.

[2] B. Halliwell, S. Chirico, Am. J. Clin. Nutr. 1993, 57, 715 S.

[3] D. Grotto, L. Santa Maria, J. Valentini, C. Paniz, G. Schmitt, S. C. Garcia, V. Juarez Pomblum, J. T. B. Rocha, M. Farina, Quim. Nova 2009, 32, 169.

[4] J. A. Drury, J. A. Nycyk, R. W. I. Cooke, Clin. Chim. Acta 1997, 263, 177.

[5] B. Cirak, S. Inci, S. Palaoglu, V. Bertan, Clin. Chim. Acta 2003, 327, 103.

[6] M. B. Kadiiska, B. C. Gladen, D. D. Baird, D. Germolec, L. B. Graham, C. E. Parker, et al., Free Rad. Biol. Med. 2005, 38, 698.

[7] V. Bergman, P. Leanderson, H. Starkhammar, C. Tagesson, Free Rad. Biol. Med. 2004, 36, 300.

[8] J. Wu, Y. Gao, Expert Rev. Proteo. 2015, 12, 623.

[9] M. Czauderna, J. Kowalczyk, M. Marounek, J. Chromatogr. B 2011, 879, 2251.
[10] J-L. Chen, Y-J. Huang, C-H. Pan, C-W. Hu, M-R. Chao, Free Rad. Biol. Med. 2011, 51, 1823.

[11] D. Tsikas, S. Rothmann, J. Y. Schneider, M.-T. Suchy, A. Trettin, D. Modun, N. Stuke, N. Maassen, J. C. Frolich, J Chromatogr. B 2015, in press.

[12] G. Zhang, Y. Tang, X. Shi, R. Gao, Y. Sun, W. Du, Q. Fu, Anal. Biochem. 2013, 443, 16.

[13] D. C. Harris in Quantitative Chemical Analysis $8^{\text {th }}$ ed. (Ed.: W. H. Freeman), New York, 2010, pp. 106-108.

[14] C. Rose, A. Parker, B. Jefferson, E. Cartmell, Crit. Rev. Environ. Sci. Technol. 2015, 45, 1827.

[15] J. N. Miller, J. C. Miller, Statistics and Chemometrics for Analytical Chemistry, 6th ed., Pearson, Harlow, 2010, pp. 127-130.

[16] A. S. Sim, C. Salonikas, D. Naidoo, and D. E. L. Wilcken, J. Chromatogr. B 2003, 785, 337.

[17] J. Lykkesfeldt, Clin. Chem. 2001, 47, 1725.

[18] Štraus, B. Medicinska biokemija, Medicinska naklada, Zagreb, 1991 (in Croatian).

[19] The Merck Index, An Encyclopedia of Chemicals, Drugs and Biologicals, 12 ${ }^{\text {th }}$ ed. (Ed.: S. Budavari), Merck Research Laboratories, Division of Merck \& CO, Inc., Whilehouse Station NJ, 1996, pp. 449-450.

[20] K-H. Lee, D. Kang, J. Prev. Med. Pub. Health 2008, 41, 195.

[21] H-N. Kil, S-Y. Eom, J-D. Park, T. Kawamoto, Y-D. Kim, H. Kim, Toxicol. Res. 2014, $30,7$.

[22] A. Kumar, B. S. Dhillon, D. N. Rao, G. Menon, H. Shankar, L. K. Dhaliwal, M. Leema, N. Chandhiok, N. Kumar, R. Sehgal, S. Mittal, S. Sahdev, K. Shobha, V. L. Jindal, Ind. J. Clin. Biochem. 2012, 27, 405. 